\title{
BREEDING SYSTEMS IN MYOSOTIS SCORPIOIDES L. (BORAGINACEAE)
}

\author{
I. SELF-INCOMPATIBILITY \\ ALICE VAROPOULOS \\ Department of Botany, The University, Whiteknights, \\ Reading, England
}

Received 18.iv.78

\begin{abstract}
Summary
Self-incompatibility in wild British populations of Myosotis scorpioides is under polygenic control; the degree of self-incompatibility varies, so that from $0-95$ per cent seed-set is obtained after self-pollination. Homozygosity at more than a critical number of loci results in complete self-incompatibility. The degree of self-compatibility is positively correlated with heterozygosity. Trinucleate pollen suggests a sporophytic type of incompatibility system but some of the characteristics of a gametophytic system, such as the site of pollen tube inhibition are seen in the species. There is no response to selection for self-incompatibility in wild French populations of $M$. scorpioides. However, upon selecting for selfincompatibility a correlated response occurred for protandry. The polygenic system can be considered as a primitive form of incompatibility system. Evolution from a more primitive, inefficient system towards greater efficiency is discussed.
\end{abstract}

\section{INTRODUGTION}

ThIS paper reports investigations on self-incompatibility in British populations of Myosotis scorpioides and comments on evolution to self-compatibility in French populations of the same species. The results are similar to those found in Medicago caerulea, Medicago sativa (Fyfe, 1957), Borago officinalis (Crowe, 1971) and in certain genotypes of Vicia faba where a mechanical barrier to pollination does not occur (Drayner, 1959). Fyfe (1957) working on the two species of Medicago found that incompatibility increased in proportion to inbreeding, a phenomenon which he described as " relational incompatibility". Crowe (1971) showed that the incompatibility system in Borago officinalis was under polygenic control. Homozygosity at more than a critical number of loci resulted in complete self-incompatibility and an appropriate combination of the polygenes resulting in heterozygosity could cause self-compatibility. This was also indicated, by the results of inbreeding, in the breeding system of Vicia faba. In the particular genotypes of Vicia faba there was a clear association of heterozygosity with selfcompatibility (Drayner, 1959).

\section{Materials AND methods}

Natural British and French populations from localities listed in the table provided sources of the original plants. Except for seven plants from Loch Lomond, which were grown from seed collected in their place of origin, all the other samples were from cuttings.

Since the interpretation of experimental data was complicated by the different degrees of self-incompatibility and it was not possible to distinguish 
TABLE 1

Origin of populations

$\begin{array}{lcc}\text { Country } & \begin{array}{c}\text { Locality } \\ \text { England }\end{array} & \begin{array}{c}\text { No. of plants } \\ \text { examined }\end{array} \\ & \text { Berkshire: River Thames } & 2 \\ & \text { Cheshire: Sandbach } & 4 \\ & \text { Gloucestershire: River Windrush } & 5 \\ & \text { Greater London: River Frays } & 12 \\ \text { Oxfordshire: River Shill Brook } & 17 \\ & \text { Oxfordshire: River Thames (Isis) } & 9 \\ \text { Warwickshire: River Avon } & 6 \\ \text { Wales } & \text { Warwickshire: River Stour } & 7 \\ \text { Scotland } & \text { Yorkshire: River Nidd } & 4 \\ \text { France } & \text { Gwynedd: River Afon } & 3 \\ & \text { Dunbartonshire: Loch Lomond } & 13 \\ & \text { Yvelines: River Geuville } & 4 \\ & \text { Yvelines: River Remarde } & 12\end{array}$

intra-incompatible, inter-compatible groups, the method applied to assess self-incompatibility was the analysis of the effect of selection, and the results are presented as a percentage of the seed-set. The highest percentage seedset recorded in experimental pollinations was 95 per cent of nutlets which is taken to represent the complete seed-set. Under natural conditions and random pollination the percentage of seed-set was commonly 100 per cent if the terminal flowers of an inflorescence were excluded. As $M$. scorpioides has different outbreeding systems, dichogamy, style length/filament length ratio, polygenic self-incompatibility and gynodioecy, combined in different ways and to different degrees, it was necessary to separate their effects. Pollen tube inhibition occurs in the base of the style as is expected in species with gametophytic incompatibility, but the pollen grains on release are trinucleate.

In order to assess accurately the percentage of seed-set after selfing by hand and to allow for protandry, the following procedure was used. One to five inflorescences from the hermaphrodite plants were bagged just before their first flower opened. The development of the inflorescences was then followed and when the first flower of the inflorescence started to wither all the open flowers (9-19 according to the population) were pollinated with pollen grains from the youngest among them. Thus, in every plant, flowers starting from anthesis till after maturity were pollinated with pollen of maximum viability. When assessing percentage of seed-set, the first flower which had a withered stigma, and a number of the last flowers (depending on the weak or strong protandry of the population), were ignored. In this way the results of different outbreeding systems were separated and coincidence of maturation of pollen and stigma was ensured as far as possible. The number of fertilised ovaries was counted after 6-10 days according to their rate of development which varied in the different populations.

\section{Results}

(i) Breeding experiments

The results of seed-set after hand selfing hermaphrodites of $M$. scorpioides from the different localities are given in the form of a histogram (fig. 1A). 
The distribution of the classes is continuous, and skewness is associated only with the British populations.

To confirm that the level of seed-set was inherited, the progeny of selfed plants with low and medium compatibility were tested. Four plants from the Yorkshire population with self-incompatibility ranging from 2.56.5 per cent were chosen as representing a category with a low seed-set. A total of 48 plants were raised and the results (fig. 2, 1-4) reveal the level of self-compatibility in the progeny. The number of classes are greatly
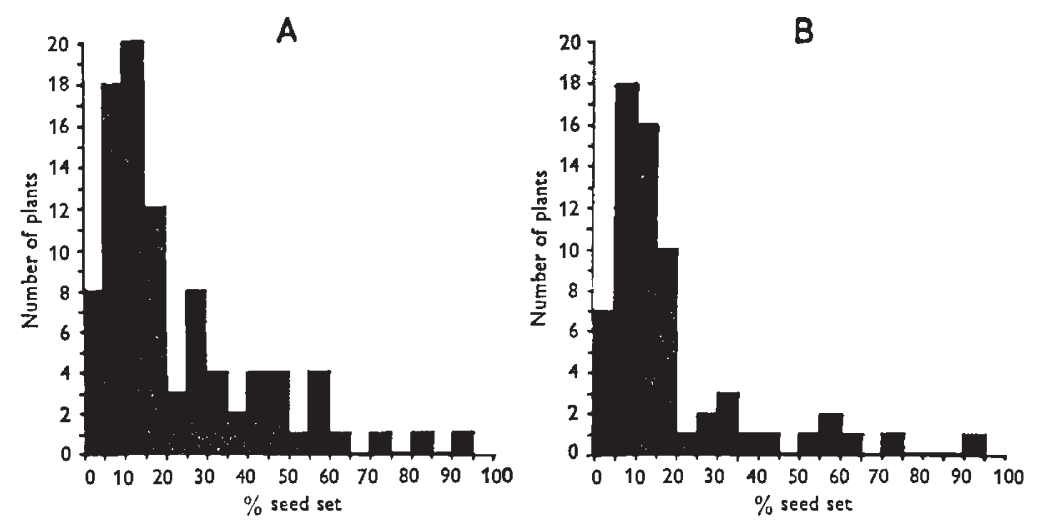

C

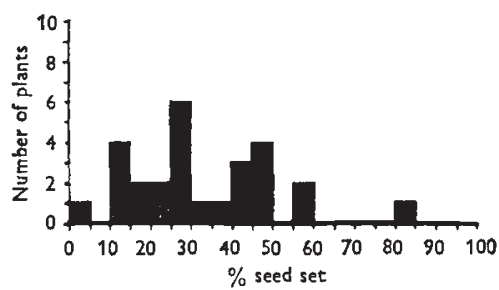

Frg. 1.-Frequency distribution showing percentage seed-set after selfing by hand in the sampled hermaphrodite plants of $M$. scorpioides: (A) Plants from British and French populations; (B) Plants from British populations; (C) Plants from French populations.

reduced, the distribution is highly skew amongst progeny of every plant and 17 out of the 48 are complately self-incompatible. Hence the selection for low percentage of seed-set had an immediate effect suggesting that the number of weak loci controlling self-incompatibility is small.

To investigate the heritable variation following cross-fertilisation, a family of six plants arising from selfing plant No. 2 were selfed and crossed reciprocally in all possible combinations (fig. 3 ). Two showed a very low self-compatibility, the remainder being completely incompatible. Thus after only two generations of inbreeding the polygenic heterozygosity had almost disappeared and the genetic control was fixed. The heritable variation in the self-compatible parents was very small.

To examine the variation in the progeny of a plant with an intermediate level of self-compatibility, the progeny of an individual from the French 
population with 49 per cent self seed-set was chosen. The results (fig. 4) gave a skew distribution with most progeny showing a lower seed-set than the parents. This unexpected distribution was subsequently found to be due to inadequate illumination. The system was tested further with three plants from the progeny, with low, medium and high seed-set $(5,25$ and
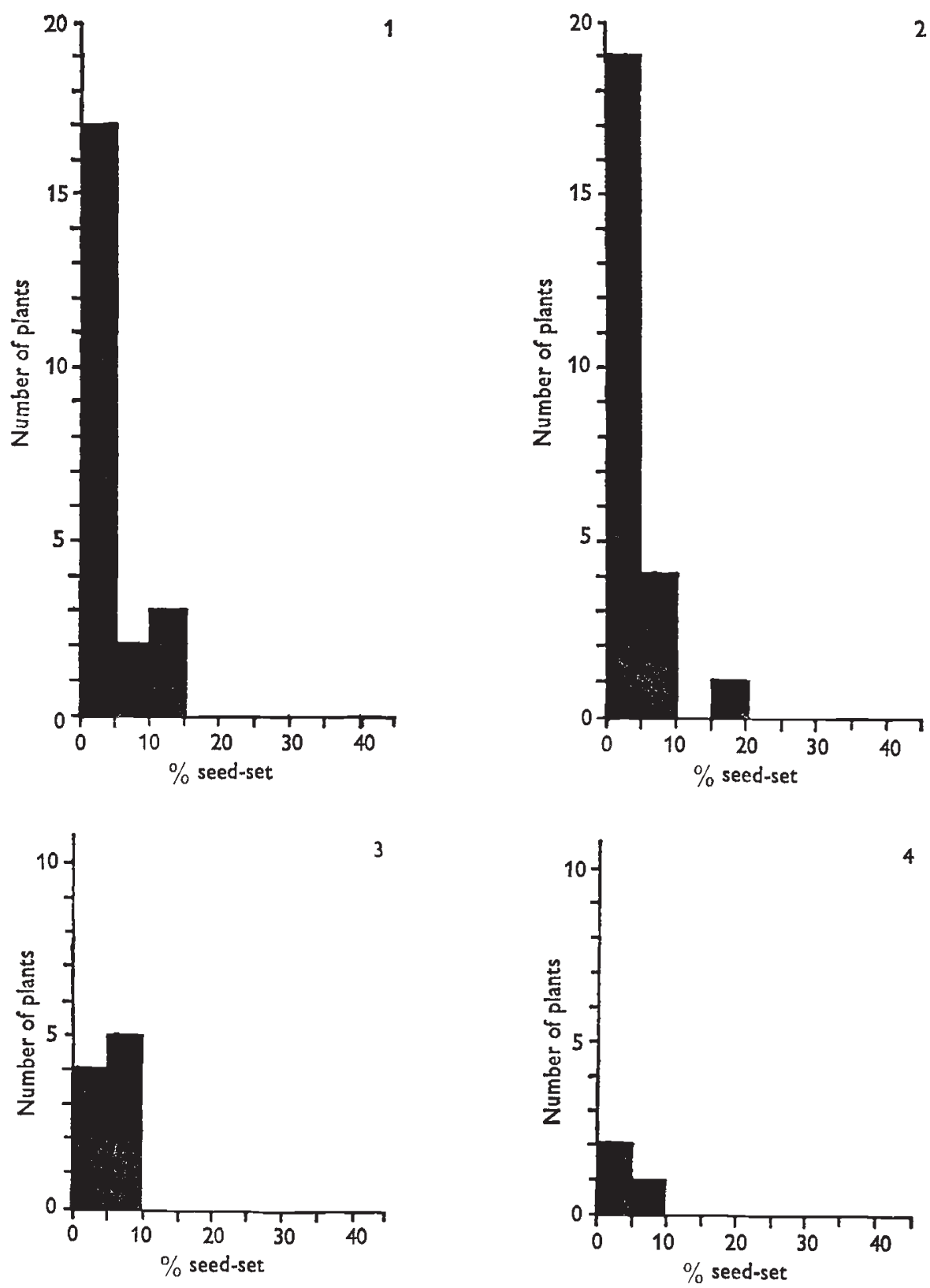

Fig. 2.-Percentage of seed-set after self pollination by hand of four highly self-incompatible plants from Yorkshire population. 


\begin{tabular}{|c|c|c|c|c|c|c|}
\hline 0 & 8 & 25 & 32 & 18 & 29 & 10 \\
\hline 8 & 0 & 0 & 0 & 0 & 0 & 0 \\
\hline 25 & 0 & 4 & 0 & 0 & 0 & 0 \\
\hline 32 & 0 & 0 & 3 & 0 & 0 & 0 \\
\hline 18 & 0 & 0 & 0 & 0 & 0 & 0 \\
\hline 29 & 0 & 0 & 0 & 0 & 0 & 0 \\
\hline 10 & 0 & 0 & 0 & 0 & 0 & 0 \\
\hline
\end{tabular}

Frg. 3.-Percentage of seed-set from crosses of six plants of the $F_{1}$ generation derived from plant No. 2 from Yorkshire population.

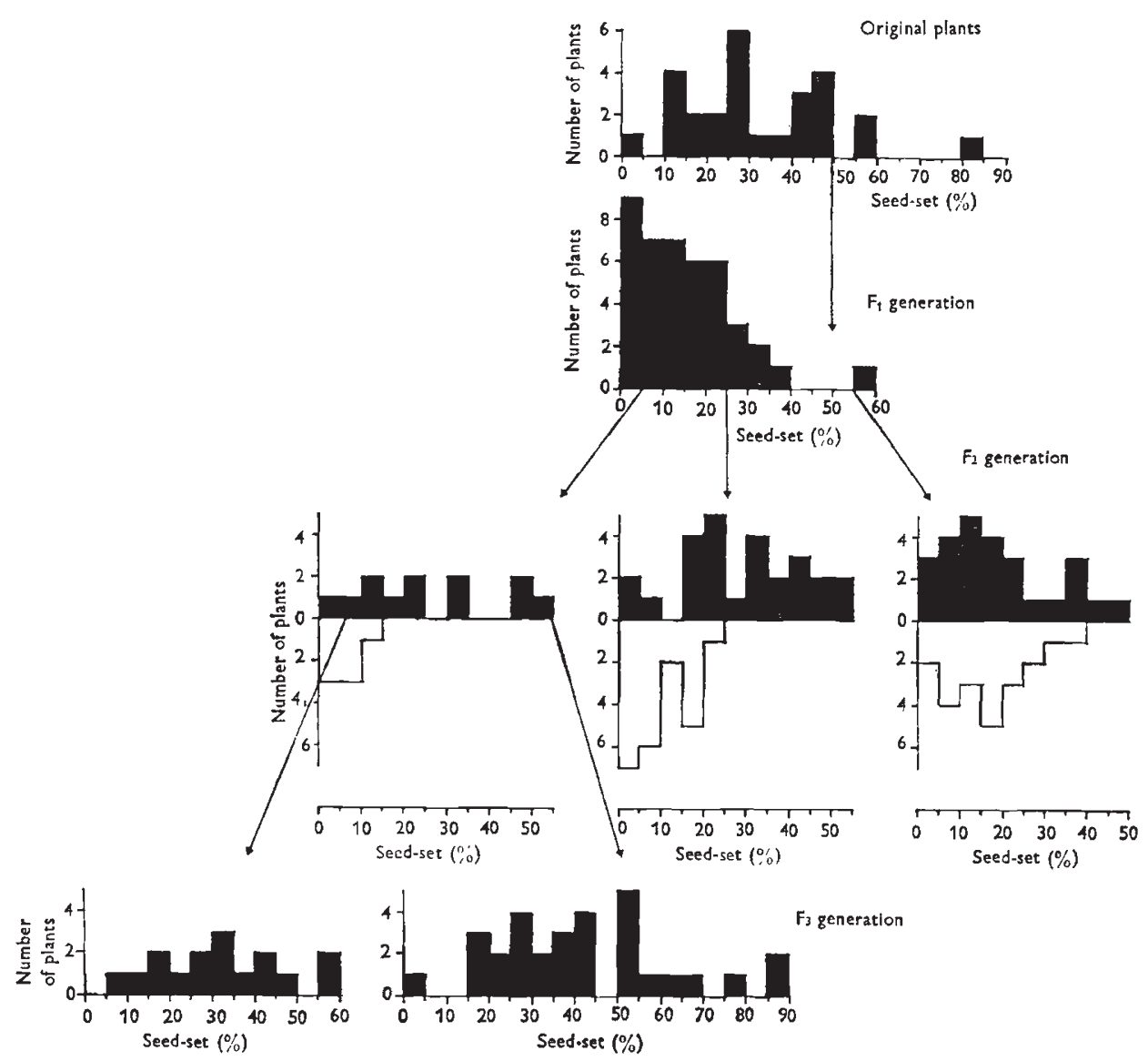

Fig. 4.-Percentage of seed-set by the original plants from French population selfed by hand with their three generations of selfing. $\mathbf{\square}=$ full seeds; $\square=$ empty seeds. 
55 per cent) selected from an area with adequate light, to raise three different families. The histograms of their percentage seed-set after selfing were essentially similar to one another and displayed continuous variation over an equally wide range. The selection experiments were continued to the $\mathrm{F}_{3}$ generation, again using plants with very different levels of selfcompatibility (6 and 55 per cent) as parents. The progeny of the two families were similar in all respects, thus making it unnecessary to continue the selection experiments. The similar distribution in the three families of the second generation and the two families of the third generation, descended from parents with very different seed-set on selfing, suggests that the limited variation in plants of French populations is not heritable. In addition the separation of the plants from the French populations from the general histogram (fig. lA) and the plotting of the special histogram for them (fig. $1 \mathrm{C}$ ) indicated that the skewness of the general distributions is due to the plants of British populations (fig. lB) and that the distribution in plants of French populations is quite normal. There is indeed no clear-cut evidence to suggest that any heritable self-incompatibility system is operating in them. The variation in seed-set may be merely a reflection of a natural range of fecundity. Therefore the study of self-incompatibility was continued with plants of the British populations only.
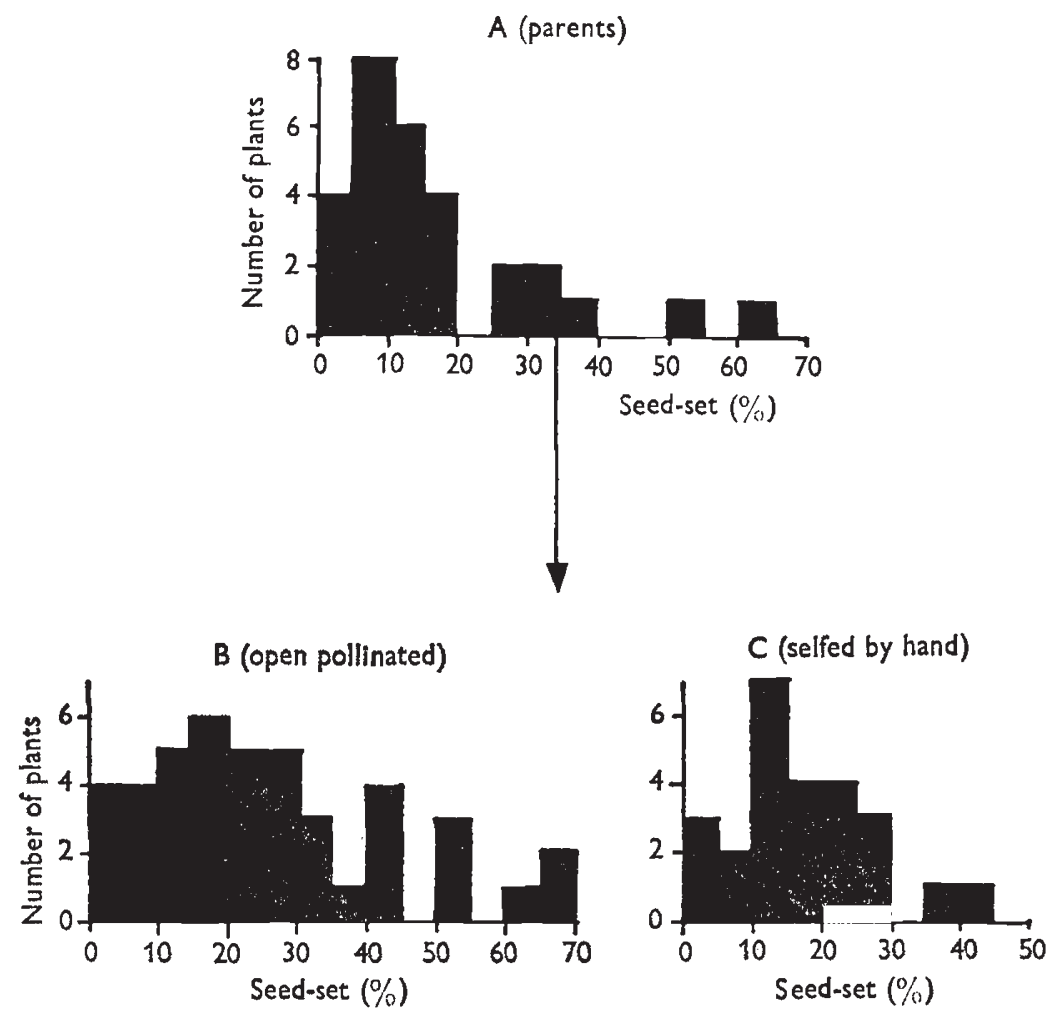

FIG. 5.-Frequency distribution of percentage seed-set: (A) Parent plants from Oxfordshire population (Shill Brook); (B) Open pollinated progeny of a single plant with intermediate self-incompatibility ( 34 per cent); (C) Progeny of the same plant self pollinated by hand. 
Seeds resulting from random pollination of a plant from River Shill Brook, with 34 per cent self-compatibility were collected in their place of origin. This plant was chosen as a parent with intermediate seed-set, and selfed by hand. The progenies from natural open pollination and selfing were raised. Histograms of their seed percentage were plotted (fig. 5) from which two conclusions were drawn. First, comparing the two histograms it was concluded that the self-incompatibility increases with inbreeding, secondly, the selfed progeny of the plant with 34 per cent self-incompatibility has a wider range than the Yorkshire population, where the selfincompatibility is very high. Therefore when the degree of selfcompatibility of the parents increases, the variation among the offspring is greater.

No evidence is available to show that the homozygosity of selfincompatible plants from widely separated populations is controlled by the same genes.

\section{(ii) Inbreeding depression}

Although the polygenic control in the plants of British populations is not entirely efficient, it acts as a satisfactory outbreeding mechanism. This is indicated by the inbreeding depression in plants of the Yorkshire population with $2 \cdot 5-6 \cdot 5$ per cent seed-set as shown by the low germination of apparently well filled seeds, also from a small reduction in vigour and the segregation of recessive mutants including chlorophyll deficient, variegated seedlings and morphological modification of the flowers. Unexpectedly, plants from French populations also showed inbreeding depression, after selfing.

\section{Discussion}

\section{(i) British populations}

Self-incompatibility in the British populations of $M$. scorpioides appears to be under polygenic control resulting in different degrees of incompatibility. There is also strong indication of environmental effects on selfcompatibility in British populations of $M$. scorpioides.

Bateman (1952) regards the polygenic system as a temporary stage in the evolution of incompatibility of the angiosperms. In the early phase of incompatibility a polygenic system allows for a smooth change towards outbreeding better than do major structural genes with their inherent rigidity (Mather and Jinks, 1971). Mather and Jinks (1971) suggested that this process provides a " continuous supply of raw material for the evolution of new structures of major and specific effect and once such a new arrangement had come into being with a major desirable action it would oust from that locus any unordered and ineffective combination, so becoming a fixed part of the genotype". Support for the above suggestion is forthcoming from the results of the artificial selection for self-incompatibility in Borago and the British populations of Myosotis. First, selection in the parent plants showed a great amount of heterogeneity which may depend on the segregation and recombination of polygenes controlling the self-incompatibility. Secondly, after several cycles of selection in progenies, when homozygosity is generated by the intrinsic inbreeding, genetic variation is reduced. In that way a more advanced system than the polygenic can be evolved, i.e. a qualitative 
system adjusted by natural selection, may gradually replace the unstable polygenic one. Many species which are in intermediate stages exemplify this gradual evolution by combining clear-cut incompatibility with different degrees of polygenic incompatibility, usually referred to or confused with, pseudocompatibility. This is clearly apparent in the recently discovered multigenic systems; for example, Larsen (1978) found that both polygenic and major-gene incompatibility coexisted in Beta vulgaris. In the Gramineae also, Lundqvist (1975) and Hayman (1956) agree that self-incompatibility is not absolute. Lundqvist (1975) concludes that this is intermediate between the indeterminate system in Borago with polygenic control and the complex S-loci system. The question of whether the number of the S-loci which can be found in the different species is fundamental and constant or whether it varies as they evolve is not yet resolved.

\section{(ii) French population}

Selection for self-incompatibility and self-compatibility in plants from French populations and from their progeny was unsuccessful, indicating that these traits are not inherited. The results of the experiments to which the British and French populations were subjected fall into two divergent categories. When polygenic control is involved in the compatibility reaction, homozygosity at more than a critical number of loci may result in self-incompatibility (Crowe, 1971). The opposite seems likely to happen in plants from the French populations. An appropriate combination of the polygenes can result in complete heterozygosity and therefore in selfcompatibility. The gradual disappearance of self-incompatibility is also demonstrated in another genus of the Boraginaceae, Amsinckia. Here the dimorphic A. grandiflora shows cryptic self-incompatibility and other different distylous species in the genus are self-compatible (Weller and Ornduff, 1977). This is also indicated in Vicia faba (Drayner, 1959). Significant evidence for this is shown by their inbreeding depression and their inherited high sensitivity to micro-environmental differences characteristic of quantitative variation (Williams, 1964). The fertility of the $F_{1}$ generation of the original French plants and their response to variable intensity of illumination (fig. 4) is a striking example of environmental effects on incompatibility.

When self-compatibility is established some hybridity can be retained through the flexibility of polygenic control, through asexual reproduction and, finally, through their extreme degree of protandry which increases in progeny derived from inbreeding. This latter condition seems to be associated especially with French $M$. scorpioides, and it appears to be a case of correlated response. It is assumed that the selection in the French plants brought changes within the polygenic combinations which affected protandry, although selection for protandry was not practised. This perhaps also explains the erratic response to selection for high fertility resulting in the skewness of the $F_{2}$ progeny derived from a parental plant exhibiting 55 per cent seed-set as shown in fig. 4; adjustment in one character affects adjustment in another (Darlington and Mather, 1949). Nevertheless, there is no divergence in the responses of the polygenic character combinations, self-fertility and protandry. The latter by allowing interfloral fertilisation for the first flowers of the inflorescence, and out- 
crossing only for the last, contribute to a smooth and gradual transition from outbreeding to inbreeding.

Acknowledgements. - I would like to thank Dr Leslie K. Crowe for her help and encouragement throughout the course of this work.

\section{REFERENGES}

Bateman, A. J. 1952. Self-incompatibility systems in angiosperms. Heredity, 6, 285-310.

CROWE, L. K. 1971. The polygenic control of outbreeding in Borago officinalis. Heredity, 27, 111-118.

DARLington, C. D., AND MATHER, K. 1949. The Elements of Genetics. Allen and Unwin Ltd., London.

DRAYNER, J. M. 1959. Self- and cross-fertility in field beans (Vicia faba Linn.). F. agric. Sci., 43, 387-403.

FYFE, J. L. 1957. Relational incompatibility in diploid and tetraploid Lucerne. Nature, $179,591-592$.

hayman, D. L. 1956. The genetic control of incompatibility in Phalaris coerulescens Desf. Aust. 7. Biol. Sci., 9, 321-331.

LARSEN, K. 1978. Quantitative modification of the compatibility reaction in Beta vulgaris $\mathrm{L}$. Incompatibility Newsletter, 9, 83-86.

LUNDQvist, A. 1975. Complex self-incompatbility systems in angiosperms. Proc. R. Soc. Lond. $B, 188,235-245$.

MATHER, K., AND JINKs, J. L. 1971. Biometrical Genetics. Chapman and Hall, London.

WELLER, S. G., AND ORNDUFF, R. 1977. Cryptic self-incompatibility in Amsinckia grandiffora. Evolution, 31, 47-51.

williams, w. 1964. Genetical Principles and Plant Breeding. Blackwell Scientific Publications, Oxford. 